\title{
Mobile gaming for agonistic design
}

\author{
Alexander Holland ${ }^{1}$ and Stanislav Roudavski ${ }^{2}$ \\ ${ }^{1}$ The University of Melbourne, Melbourne, Australia \\ alexholland@me.com \\ ${ }^{2}$ The University of Melbourne, Melbourne, Australia \\ stanislav.roudavski@cantab.net
}

\begin{abstract}
This paper demonstrates how mobile games can contribute to participatory design and its aim of achieving positive change through the involvement of stakeholders. This overarching goal is considered via a particular case-study that utilizes a purpose-built smartphone game. The case-study applies this game to the design challenges of urban cycling. Utilisation of the game in a stakeholder workshop suggests that mobile play can aid understanding and help to establish communication amongst diverse participants. For further information and media, see https://osf.io/vy5dq/
\end{abstract}

Keywords: mobile games; urban cycling; participatory design; infrastructuring; urban design.

\section{Participatory design toolkits}

"What are we looking at? Are we there? We're in it? On that bike?" Participant A, first reaction to PocketPedal.

This paper engages with agonistic characteristics of participatory design or "constructive controversies among 'adversaries' who have opposing matters of concern but also accept other views as 'legitimate'." (Björgvinsson et al., 2010, p. 48) In the presence of such controversies, design can be understood as a negotiation of social change between individuals, social contexts and design artefacts (Latour, 2005). Consequently, an important objective of participatory design is to promote the negotiation of social change for the production of critical alternatives rather than objects or products (Gerrard and Sosa, 2014).

Construction of conditions needed for such negotiations has been described as infrastructuring, or the aligning of inscribed norms and values across contexts through socio-material negotiations. (Star and Bowker, 2006[2002]; Karasti et al., 2010) This search for alignment is motivated by the recognition that physical construction will not be supported without a cultivation of fertile social infrastructure (Clement et al., 2012; Karasti, 2014). This type of infrastructure sustains and enables dreams of the new. It consists of knowledge, know-how and institutions, existing as dynamic fabrics of relationships - a kind of ecology. Successful establishment of such infrastructure depends on the construction of a "common language" (Neumann and Star, 1996). The toolkit discussed in this paper aims to assist with this shared languaging. 
This commonality does not necessarily resolve as a consensus, or even compromise. Instead, the nonexistence of a single homogeneous public and the resulting agonism can be seen as a norm. Consequently, in conditions of agonistic democracy (Mouffe, 2005), the goal is not consensus, but the discovery and cultivation of commonalities. Such commonalities can manifest as "boundary objects" (Star and Griesemer, 1989) that can inhabit different communities of practice. These objects can be used and understood differently by different groups but retain their identity across sites. Stakeholders can "colonize" such objects for the "collective creation of values". Work discussed below seeks to activate such boundary objects through the introduction of mobile-game worlds as shared 'design things' (Ehn, 2008).

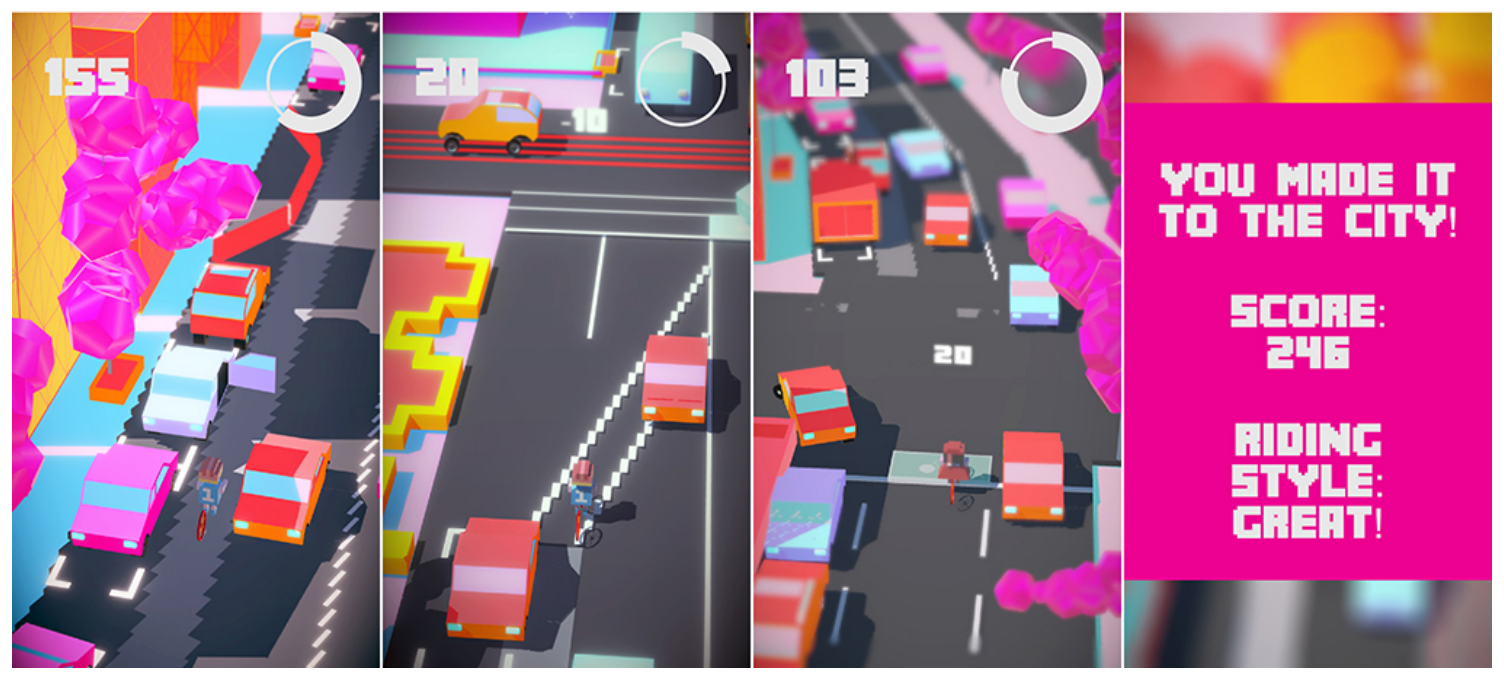

Figure 1. In game images. I: an open door blocks the player's path.

II and III: difficult intersections - in order to make room for left hand vehicles, the player must move across lanes of traffic. IV: the player has successfully navigated the level.

"[A]II people are creative and can contribute to design if provided an appropriate setting and tools" (Vaajakallio and Mattelmäki, 2014). Design games can act as such tools, and help stakeholders explore the world and its future states (Lerner, 2010; Sanders and Stappers, 2014) making solutions more probable (Brandt, 2006; Vaajakallio and Mattelmäki, 2014) in the processes identified above as infrastructuring.

Computer games can further extend the capabilities of design games (von Borries et al., 2007; Lerner, 2014), and are effectives as tools for social inclusion (European Commission's Joint Research Centre et al., 2013). Yet, their detailed environments can be less open to individual interpretation than board or parlour design games (Brandt and Messeter, 2004). Furthermore, stationary videogame systems can exclude nongamers, requiring dedicated spaces and knowledge of unfamiliar conventions and demanding controllers.

At the moment of writing, the accessibility of games is being redefined by portable devices such as smartphones. Games running on such devices can be played in diverse locations and social situations by much broader publics. Such 'mobile' games have been used in the context of design - for example, for exploration (Ehn et al., 2014), the education of planners (Valdez Young, 2013), or to demonstrate the interrelationship between games and cities (de Souza e Silva and Hjorth, 2009). However, a review of 
current literature indicates that purposeful application of games for infrastructuring, and more specifically to the construction of common languages in the context of intractable design problems, has not been previously attempted. Development of possibilities promised by this approach is the focus of this paper.

\section{Urban cycling as an agonistic test-case}

“It's kind of continual, isn't it? It's just continual drip drip annoyance. It's not one particular thing, it's all the time." Participant B, attempting to articulate the problems of St Kilda Road.

As its case-study, this paper considers St Kilda Road, a busy commuter corridor with inadequate cycling provisions in Melbourne, Australia. The challenges of tackling urban cycling are appropriate as a casestudy because of their similarity to other design problems involving multiple and diverse stakeholders. To date, conventional design approaches have been ineffective in improving the road's cycling conditions. Research discussed in this paper seeks to consider viable extensions to the established design methods.

According to a recent report, on an average day, St Kilda Road is used by 41,000 vehicles, 200,000 tramway passengers and 3,000 cyclists (GHD, 2014). Such traffic exceeds governmental recommendations for when bicycles and cars should be physically separated (Austroads, 2011). In contradiction to these guidelines, cycling provisions along the route consist of lanes painted onto the road. These lanes are narrow, discontinuous at intersections, and, in some places, cross multiple streams of motor traffic. Such road conditions lead to physical collisions and social hostilities. This is recognised by cycling support groups (Bicycle Network Victoria, 2000) and governmental organisations (Austroads, 2011) alike, yet proposals to isolate cyclists from vehicles have not been implemented. The rest of this section describes typical design challenges of this situation and establishes directions for subsequent exploration.

\subsection{Understanding complexity}

The first of these directions emphasises the highly complex nature of typical design challenges that cannot be easily represented by numerical data. In the period of 2010-2015, VicRoads, the governmental road authority, recorded 122 crashes involving cyclists along St Kilda Road, one of the highest collision rates in the state (VicRoads, 2016). These included the following common events: 1) DCA 163 'vehicle door' event occurring when a driver or passenger in a parked car opens a door in the path of a passing cyclist. A study commissioned by the Road Safety Action Group found that all cyclists observed along St Kilda Road ride within car door swings (CDM Research, 2015); and 2) DCA 167 'Left turn side swipe', an event occurring when a vehicle veers into a cyclist when attempting to turn off/on St Kilda Road, mostly at intersections. The primary cause of such incidents are motorists unware that a cyclist is riding between them and the kerbs (Johnson et al., 2010).

While useful, such statistics cannot portray near misses, the context of accidents or stakeholder behaviours, and can distort the character of events through rigid categorisation. For example, an incident involving a cyclist coming off a bike as the result of needing to avoid a suddenly opened car door might be classified as the generic DCA 174 Out of Control on a Carriageway, rather than as a dooring incident. In other cases, efforts to reduce kerbside side-swipe collisions by implementing left-hand turning lanes at intersections force cyclists to merge with streams of centre-lane traffic. The complex chains of events surrounding the resulting events can be lost during data collection and classification.

Moreover, it has been estimated that only 1 in 30 non-fatal cyclist crashes in Victoria are reported to the police (Harman, 2007). Crashes are usually recorded by police when assessing property damage after the event. Therefore, it can be difficult to report crashes that did not affect the vehicle, but have caused 
significant injury to a cyclist (Monash University Accident Research Centre et al., 2012; Amy Gillett Foundation et al., 2015). This paper suggests that these observations highlight the need for analysis and design tools that can better engage with urban cycling as a complex situation and a holistic experience.

\subsection{Engaging with diversity}

The second direction explored in this paper acknowledges that complex design challenges can be experienced differently by different stakeholders. For example, the Amy Gillett Foundation's report (2015) demonstrates that current reporting mechanisms do not recognise the varied travel experiences of drivers and cyclists. On the road, cyclists are more vulnerable than drivers (Monash University Accident Research Centre et al., 2012), navigating through the urban environment in a different manner than motorists. This situation is not only stressful for cyclists, who expose themselves to higher chances of harm, but also for drivers, who must interact with road users with unfamiliar and potentially unpredictable behaviours. This 'traffic stress' differs not only between types of road users but also between genders (Garrard et al., 2008) and individuals (Mineta Transportation Institute et al., 2012).

Such differences effect on-road events (Vanlaar et al., 2008) and, consequently, cyclist safety (Aultman-Hall and Hall, 1998). Studies indicate that awareness and empathy improve road safety. For example, the likelihood of collisions between cars and motorcycles decreases not only when a car driver rides a motorcycle him/herself, but also when a driver simply knows someone who does (Crundall et al., 2008). Accordingly, design and consultation tools need the ability to present complexity from multiple points of view, providing experiences that might otherwise be inaccessible to key stakeholders.

\subsection{Communicating accessibly}

Examples of how the propagation of knowledge through friends or families helps to develop more nuanced understandings of complex situations affirm the need for effective communication. To reduce the frequency of crash events along St Kilda Road, campaigns have attempted to inform drivers by attaching 'watch out for bike' stickers to vehicle doors (Bolitho, 2013), and installing temporary warning signs (CDM Research, 2012), without success. Such studies point out that personal stories are more likely to bring change than deterrents such as general warnings or fines. At the same time, it has been shown that effective road-user education is essential for the promotion of cycling and cycling safety. This teaching needs to focus on cyclists (Australian Government's Department of Health and Ageing et al., 2008) but also on the general public who need to "be educated about the severity of the pedestrian and bicyclist crash problem and the urgent need to deal with it. [...] Instead of being viewed as punitive measures aimed against motorists, [bicycle-safety measures] should be presented as new opportunities for all segments of the population." (Pucher and Dijkstra, 2000, p. 30). Consequently, this paper argues that there is a need is for new tools that can communicate complex situation to a variety of stakeholders in an intuitive, memorable and emotionally relevant manner.

\section{A game of urban cycling}

"There are a lot of dangers for cyclists out there in Melbourne today - such as cars parked on the bike lane, which stop you getting a high score!" Participant $C$, reflecting on his ride.

The research discussed in this paper engages with one particular type of tool, a mobile game that simulates urban cycling. Called PocketPedal, this game was developed to understand how design can benefit from the integration of interactive and situated technologies. 
PocketPedal is a single-player, real-time, quick-paced 3D game that runs on smartphones. The player's objective is to traverse a segment of St Kilda Road without crashing, cycling safely to obtain a high score. The player is present in the game as an avatar of a cyclist. The game randomly assigns a new avatar at each run, for example a middle aged man in lycra (MAMIL); a young male office worker; or a female university lecturer. The player attempts to reach the city one ride at a time, negotiating through increasingly difficult challenges. Each attempt is short, from tens of seconds to several minutes. Players aim to improve their score through multiple attempts. The game does not require introductory tutorials; on-screen messages give suggestions and provide feedback as required. An attempt is terminated if the player reaches the city or if the avatar experiences a serious collision [Figure 1.IV]. At that moment, the game presents an assessment of the completed ride or a description of the injury and restarts.

PocketPedal's environment is made of colourful, blocky objects. Players access the game via a thirdperson camera view, seeing the road from an overhead perspective [Figure 1.I]. The camera shows a limited fragment of the road constraining forward planning [Figure 1.I]. A shallow depth-of-field effect blurs distant objects, further limiting perception [Figure 1.I, top left corner].

The game implements the following 'objects': 1) Avatar: a representation of a cyclist whose motion is informed by a physics simulation. 2) Route: a precarious on-road bicycle path that proceeds between parked vehicles and lanes of motor traffic [Figure 1.I, central area]. 3) City: a two-kilometre section of St Kilda Road with a river, a main bridge, major landmarks, surrounding buildings, landscaping and road furniture [Figure 1.I]. 4) Roads with comprehensive road markings, vehicular and cycling lanes, cyclist stopping areas before intersections, tramways, intersections and other features. 5) Vehicles are organized into automated traffic moving according to road rules. Density of the traffic represents actual on-road conditions. There are vehicles of different types - cars, trucks, buses, etc. - with different driving patterns and access permissions. Based on realistic probabilities, the vehicles are ascribed types of driving behaviours ranging from obedient to aggressive. Stationary vehicles are generated at parking spaces located between the path and the kerbs. Depending on their size and behaviour they can partially obstruct the bicycle lane. Vehicles can also double-park, blocking the bicycle path completely. Stationary vehicles can also open their doors when the avatar cycles past.

Players interface with the game through touch. Tapping the centre of the screen makes the avatar pedal forward. Tapping the edges controls turning, and a down swipe initiates breaking. The player's performance is represented by two numbers. The first, the score [Figure 1.II, top left corner], aggregates with distance, while the second [Figure 1.II, top right corner] acts as a multiplier that accelerates or decelerates the rate with which the score changes. This multiplier represents the quality of the player's riding and is increased when the player stays in the bicycle lane, or navigates through other cycling provisions such as stopping boxes [Figure 1.III, central area]. When the player leaves the lane - or is too close to a hazard - the quality multiplier decreases, and the rate of point aggregation is reduced. If the multiplier is at zero, the player stops gaining points and cannot increase his/her score.

\subsection{Game mechanics and participatory design objectives}

PocketPedal provides an immersive experience of the road. As described earlier, cycling collisions are not discrete incidents. Crashes instead occur as sequences of events in dynamic and interconnected environments. In a game like PocketPedal, these sequences can be persuasively replicated.

For example, [Figure 1.I, central area] shows the open door of a parked car blocking the path, requiring the player to leave the kerbside and merge with fast moving traffic. The proximity of car parking spaces 
to unprotected bicycle lanes is problematic not only because of the ever-present danger of 'dooring' but also as a source of continually accumulating stress and its effects. Unlike statistical surveys, PocketPedal represents not only the unitary events of serious collisions but also the context: cognitively demanding navigational tasks; reasons for sudden direction changes; and the need for making choices between similarly unattractive options, all under pressure. Often, the apparently erratic behaviour of a cyclist (or a player) can be explained by the accumulated frustration of having to slow down or stop to comply with the rules and provisions of the road that might seem illogical, unreasonably dangerous and unfair.

The game also provides an opportunity to replay the same situation in quick succession, supporting the accumulation of knowledge, experiences and skills that are hard to achieve with other tools or on the real-world road. The virtual road can provide such experiences because of its automated traffic that is based on observed driving behaviour. 'Aggressive' vehicles are (Walker et al., 2014) are blind to the player and change speeds quickly, drifting in and out of their lanes and swerving suddenly. 'Cautious' vehicles, on the other hand, accelerate slowly, remain in their lane and are responsive to the player, slowing down several metres behind the avatar and other vehicles. Novel events reliably arise from the interaction between the spatial conditions, the player and differentiated non-player road users. For example, in PocketPedal, side-swipe collisions are produced by the 'tunnel vision' where automated vehicles focus on the events in front of them and are likely to miss an avatar at the side, like in real life. Real-world events of this kind were discussed in the section on urban cycling and emerge in the game not as predetermined occurrences but as an emergent effect of local interactions. Generated in response to local conditions, such events are always different. They can happen at low or high speeds, in different lanes, at straight sections or during turning. To the player, these collisions might appear as unfortunate accidents, products of irresponsible driving by the motorists, hard-to-avoid errors induced by the challenging driving conditions, or bad personal decisions.

Another example of the effects produced by game mechanics relates to the scoring system. This system encourages players to become invested in their avatar's success, facilitating active engagement. Moments such as when a bicycle lane disappears [Figure 1.III], or when multiple parked vehicles block the path, are made frustrating because players have no choice but to accept a reduced score. In other cases, players with good scores may ride faster and more recklessly, confident that their score is already high. Finally, players, wanting to better a previous score, might employ new navigation methods. These discovered behavioural changes could be tactical - moderating the speed more carefully - or strategic, such as ignoring potentially dangerous cycling infrastructure [Figure 1.II, 1.III]. As the game is intended to support short, repeated attempts, players are encouraged to experiment with many methods and approaches that would be much harder or impossible to try on a real road.

To conclude, even when experienced by an individual player, the mechanics of PocketPedal create a magic circle (Huizinga, 1949[1944]) within which players can be safely exposed to the physical (Garrard et al., 2010) and emotional (Aldred, 2012) challenges of cycling. However, the design of PocketPedal presumes its immersion into the context of social play and the additional effects possible through such integration are discussed in the subsequent section.

\subsection{Mobile gaming for infrastructuring}

How can a game act as a boundary object? Can it provide enhanced capabilities to "align the participants around a shared, though problematic or even controversial, object of concern" (Ehn, 2008, p. 93)? To support such alignment, PocketPedal is intended to be experienced collectively. The observations presented here are derived from a workshop that included cyclists, drivers, workers, doctors and planners. 
During the workshop, stakeholders participated in a series of curated activities. Data was collected through video recordings, interviews and questionnaires, before, during, and after the event.

This social context of group play in a shared physical location provides for a dramatically extended repertoire of play patterns, especially in the case of mobile games played on portable devices. For example, a mobile game can be controlled by a group suggesting actions, played by individuals in parallel, exchanging remarks; played in turns, with debriefings or competitively; demonstrated and commended on by experienced players; framed by other games or activities and so on. In the words of Participant D, observing the workshop group:

"The game is a great leveller, with drivers and cyclists meeting in more neutral ground."

The rest of this section presents two beneficial effects of curated social play: 1) 'nested play' and 2) 'parallel play'.

Nested play inserts PocketPedal into other activities, exposing players to multiple modes of interaction. This curated embedding encourages direct and incidental communication, extending the capabilities of the in-game mechanics. For example, in the workshop, the game was preceded by 'warmup' activities including: 1) a quiz where participants had to match slides of game scenes with city locations; 2) a sorting task, where participants had to label themselves as types of road users; 3 ) a 'reverse interview' where pairs of participants had to ascribe behaviours to one another; 4) an activity where participants had to analyse a movie of the road; and 5) a card game that asked players to organise photographs into different types of cycling journeys. Such activities interfaced people that do not typically meet and encouraged them to engage with subtleties of their existing preconceptions. Beyond that, these warm-up exercises allowed exploration of alternative and possibilities. Such explorations helped participants to appreciate game environments in greater nuance than was warranted by in-game geometry or automation. The contexts of the varying out-of-game experiences discussed during these curated activities also lead to reconsiderations of in-game events in reference to other locations and situations.

Further nesting encouraged players to engage with each other and with different capabilities of the game. Collaborative play saw one player guiding their avatar at the instructions of the group, requiring participants to negotiate a shared goal, at speed, and with immediate consequences. Other activities paired a playing participant with an observer, who documented their attempts and then recounted his/her observations. Role-switching between actors and spectators challenged players to come into new social relationships and develop novel understandings.

"Oh you are a lycra person - alright, speed up!", Participant B observing another player.

'Cool-down' activities included: 1) a roundtable where participants discussed hopes and ideas for future change, 2) a questionnaire were participants answered questions around their game experience, and 3) follow-up interviews conducted a week after the event. Cumulatively, these activities provided an opportunity for collaborative reflection: sharing of experiences, comparisons of interpretations and the voicing of thoughts on future design possibilities. As it was mentioned by Participant $D$, "approaching the issue in an unorthodox way enabled the opportunity for novel ideas."

Within this context, parallel play is a set of deliberately curated relationships made possible by the mobile nature of the game. Although experienced collectively, the phones with PocketPedal city are carried personally: a reversal of one's normal relationship with the urban, which exists as a shared entity that is experienced by individuals. This configuration offers several benefits for infrastructuring. Firstly, portability allows for virtual experiences to be staged anywhere, at any time. In the context of the 
workshop, players could interact with the game in any space, with any participant, as groups or individuals, easily rearranging. At one time several participants could play as individuals; others in a small group, standing near the window, while the rest preferred the sunny outside. The familiarity of the phones helped non-gamers - most of the workshop group - feel at ease as players. Instead of being intimidated by unfamiliar activities, parallel smartphone play facilitated rapport and creativity - triggering laughter, excitement and the formation of friendly rivalries.

Participant A, not so familiar with games, isn't going so well: ending her ride in a high-speed crash. The music slows down and becomes sombre. 'You crashed!' the game flashes. 'You've ended up with a sad family!' Participant B, in another group, turns around to offer condolences. 'I hit a truck', she sympathises, 'I was going too fast'.

Such interactions are an example of parallel action. When playing PocketPedal, some players moved together, comparing riding conditions in tight groups. Others, hearing laughter and commotion, would become curious and roam. To see the small screens, players needed to move closer, provoking spontaneous interactions. These could be as simple as pointing out an unseen hazard on another's screen, leaning over to commiserate over a crash, or expressing mock dismay at the low amount of traffic another is facing in comparison with that in their journey. On the other hand, the interactions could be more sophisticated when sharing a personal memory or discussing the political context.

It is impossible to completely know, or 'fix', complex systems because they can result in pragmatically useful but incompatible knowledges. (Bucciarelli, 2009). Yet, in the words of Participant D,

"[Playing the game in the workshop] made the issues seem more tangible, approachable and open to change, [going beyond] the general opinion that cycling infrastructure is bad as a whole and therefore too large a problem to fix."

Collaborative mobile games allow stakeholders to co-play through issues via immersive simulations that support spontaneity and improvisation in combination with curation. To conclude, curated and embedded, the game emerges as a provocative boundary object that can highlight issues of concern and establish common languages without dismissing actual disagreements.

\section{Steps towards a common language}

"That's obviously the ex-husband", Participant A, noting an aggressive vehicle manoeuvre.

The magic circle of play is attractive and powerful because it gives access to the unlikely and the impossible. However, this magic can also isolate players from the everyday world, transposing them into a distinctly otherworldly state. By contrast, strategies discussed in this paper seek to capitalise on the characteristics of curated play to establish common languages that link stakeholders to real-world issues while maintaining the 'magic' of playing. Such languages are necessary for social infrastructuring and, consequently, for the emergence and adoption of viable design decisions. The discussion of mobile gaming in application to the design challenge of urban cycling demonstrates that these games hold exciting promise as tools for participatory design. They are able to facilitate better communication by acting as immersive and engaging boundary objects. The shared engagement with these boundary objects leads to greater inclusion of diverse stakeholders and the development of rapport that is necessary for a deeper understanding of the experiences and needs of others. With this, games can contribute to more nuanced appreciations of complex design situations and the subsequent construction of platforms for change. 


\section{References}

Aldred, R. (2012) Incompetent or Too Competent? Negotiating Everyday Cycling Identities in a Motor Dominated Society, Mobilities, 8, 252-271.

Amy Gillett Foundation, Garrat, M., Johnson, M., et al. (2015) Road Crashes Involving Bike Riders in Victoria, 20022012: An Amy Gillett Foundation Report, Amy Gillett Foundation, Melbourne.

Aultman-Hall, L. and Hall, F. (1998) Ottawa-Carleton Commuter Cyclist On- and Off-Road Incident Rates, Accident Analysis and Prevention, 30(1), 29-43.

Australian Government's Department of Health and Ageing, Bauman, A., Rissel, C., et al. (2008) Cycling: Getting Australia Moving: Barriers, Facilitators and Interventions to Get More Australians Physically Active through Cycling, Cycling Promotion Fund, Melbourne.

Austroads (2011) Cycling Aspects of Austroads Guides, Austroads, Melbourne.

Bicycle Network Victoria (2000) Cycle Notes No.7: On-Road Arterial Bicycle Routes, VicRoads, Melbourne.

Björgvinsson, E., Ehn, P. and Hillgren, P.-A. (2010) Participatory Design and 'Democratizing Innovation', PDC 10: Proceedings of the 11th Biennial Participatory Design Conference, edited by T. Robertson, Sydney, AU, 29 November - 3 December, 41-50.

Bolitho, J. (2013) A Multi-Stage, Multi-Faceted Approach to Addressing 'Car Dooring' in Inner Melbourne, Australasian College of Road Safety Conference, 2013, Adelaide, South Australia, Australia.

Brandt, E. (2006) Designing Exploratory Design Games, Proceedings of the Ninth Conference on Participatory Design: Expanding Boundaries in Design, edited by G. Jacucci and F. Kensing, New York, 57-66.

Brandt, E. and Messeter, J. (2004) Facilitating Collaboration through Design Games, Proceedings of the Eighth Conference on Participatory Design, 1, 121-131.

Bucciarelli, L. L. (2009) Designing Engineers, in H. Clark and D. E. Brody (eds.), Berg, Oxford, 81-95.

CDM Research (2012) Bicycle Rider Collisions with Car Doors, Road Safety Action Group Inner Melbourne, Melbourne.

CDM Research (2015) Evaluation of Car Dooring Intervention on St Kilda Road, Road Safety Action Group Inner Melbourne, Melbourne.

Clement, A., McPhail, B., Smith, K. L., et al. (2012) Probing, Mocking and Prototyping: Participatory Approaches to Identity Infrastructuring, Proceedings of the 12th Participatory Design Conference: Research Papers - Volume 1, Roskilde, Denmark, 21-30.

Crundall, D., Bibby, P., Clarke, D., et al. (2008) Car Drivers' Attitudes Towards Motorcyclists: A Survey, Accident Analysis and Prevention, 40, 983-993.

de Souza e Silva, A. and Hjorth, L. (2009) Playful Urban Spaces: A Historical Approach to Mobile Games, Simulation \& Gaming, 40(5), 602-625.

Ehn, P. (2008) Participation in Design Things, Proceedings of the Tenth Anniversary Conference on Participatory Design, Bloomington, Indianna, 92-101.

Ehn, P., Nilsson, E. M. and Topgaard, R. (2014) Making Futures: Marginal Notes on Innovation, Design, and Democracy.

European Commission's Joint Research Centre, Stewart, J., Bleumers, L., et al. (2013) The Potential of Digital Games for Empowerment and Social Inclusion of Groups at Risk of Social and Economic Exclusion: Evidence and Opportunity for Policy, European Union, Luxembourg.

Garrard, J., Greaves, S. and Ellison, A. B. (2010) Cycling Injuries in Australia: Road Safety's Blind Spot?, Journal of the Australasian College of Road Safety, 21, 37-43.

Garrard, J., Rose, G. and Lo, S. K. (2008) Promoting Transportation Cycling For Women: The Role of Bicycle Infrastructure, Preventive Medicine, 46, 55-59.

Gerrard, V. and Sosa, R. (2014) Examining Participation, edited by H. Winschiers-Theophilus and V. D'Andrea, Windhoek, NM, 6-10 October, 111-120.

GHD (2014) Port Philip City Council Separated Bike Lanes: St Kilda Road Cost Benefit Analysis, GHD, Melbourne.

Harman, B. (2007) Bicycle Law Enforcement, Australasian Road Safety Research Policing Education Conference: Infants, Children and Young People and Road Safety, edited by F. Ian, Sydney, AU, 2-3 August, 6.

Huizinga, J. (1949[1944]) Homo Ludens: A Study of the Play-Element in Culture, Routledge and Keagan Paul, London. 
Johnson, M., Charlton, J., Oxley, J., et al. (2010) Naturalistic Cycling Study: Identifying Risk Factors for On-Road Commuter Cyclists, Annals of Advances in Automotive Medicine, 54, 275-283.

Karasti, H. (2014) Infrastructuring in Participatory Design, Proceedings of the 13th Participatory Design Conference, edited by H. Winschiers-Theophilus and V. D'Andrea, Windhoek, Namibia, 141-150.

Karasti, H., Baker, K. S. and Millerand, F. (2010) Infrastructure Time: Long-term Matters in Collaborative Development, Computer Supported Cooperative Work (CSCW), 19(3-4), 377-415.

Latour, B. (2005) From Realpolitik to Dingpolitik or How to Make Things Public, in B. Latour and P. Weibel (eds.), MIT Press, Cambridge, MA, 4-31.

Lerner, J. (2010) What Games Can Teach Us about Community Participation: Participatory Urban Development in Rosario's Villas, Places We Live: Slums and Urban Poverty in the Developing World.

Lerner, J. (2014) Making Democracy Fun: How Game Design Can Empower Citizens and Transform Politics, MIT Press, Cambridge, MA; London.

Mineta Transportation Institute, Mekuria, M. C., Furth, P. G., et al. (2012) Low-Stress Bicycling and Network Connectivity, Mineta Transportation Institute, San José, CA.

Monash University Accident Research Centre, AlfredHealth, Biegler, P., et al. (2012) Monash Alfred Cyclist Crash Study (MACCS), Monash University Injury Research Institute, Alfred Health, Melbourne.

Mouffe, C. (2005) On the Political, Routledge, Abingdon.

Neumann, L. J. and Star, S. L. (1996) Making Infrastructure: The Dream of a Common Language, Participatory Design Conference, edited by J. Blomberg, F. Kensing and E. Dykstra-Erickson, Cambridge, MA, 231-240.

Pucher, J. and Dijkstra, L. (2000) Making Walking and Cycling Safer: Lessons from Europe, Transportation Quarterly, 54(3), 25-50.

Sanders, E. B. N. and Stappers, P. J. (2014) Probes, Toolkits and Prototypes: Three Approaches to Making in Codesigning, CoDesign, 10(1), 5-14.

Star, S. L. and Bowker, G. C. (2006) How to Infrastructure, in L. A. Lievrouw and S. Livingstone (eds.), Handbook of New Media: Social Shaping and Social Consequences of ICTS, Sage, London, 230-245.

Star, S. L. and Griesemer, J. R. (1989) Institutional Ecology: 'Translations' and Boundary Objects: Amateurs and Professionals in Berkeley's Museum of Vertebrate Zoology, 1907-39, Social Studies of Science, 19(3), 387-420.

Vaajakallio, K. and Mattelmäki, T. (2014) Design Games in Codesign: As a Tool, a Mindset and a Structure, CoDesign, $10,63-77$.

Valdez Young, A. (2013) Play to Plan: Mobile Games to Value Street-Level Trade. Available from: <http://ethnographymatters.net/blog/2013/03/29/play-to-plan-mobile-games-to-value-street-level-trade/> (accessed 9/27/2016).

Vanlaar, W., Simpson, H., Mayhew, D., et al. (2008) Aggressive Driving: a Survey of Attitudes, Opinions and Behaviors, Journal of Safety Research, 39, 375-381.

VicRoads (2016) Crash Stats Dataset. Available from: Government of Victoria $<$ https://www.data.vic.gov.au/data/dataset/crash-stats-data-extract> (accessed 2016-06-06).

von Borries, F., Walz, S. P. and Böttger, M. (eds.) (2007) Space Time Play. Computer Games, Architecture and Urbanism: The Next Level, Birkhäuser, Basel.

Walker, I., Garrard, I. and Jowitt, F. (2014) The Influence of a Bicycle Commuter's Appearance on Drivers' Overtaking Proximities: An On-Road Test of Bicyclist Stereotypes, High-Visibility Clothing and Safety Aids in the United Kingdom, Accident Analysis and Prevention, 64, 69-77. 


\section{University Library}

\section{- M M I E E R VA A gateway to Melbourne's research publications}

Minerva Access is the Institutional Repository of The University of Melbourne

Author/s:

Holland, A;ROUDAVSKI, S

Title:

Mobile Gaming for Agonistic Design

Date:

2016

Citation:

Holland, A. \& ROUDAVSKI, S. (2016). Mobile Gaming for Agonistic Design. Zuo, J (Ed.)

Daniel, L (Ed.) Soebarto, V (Ed.) pp.299-308. The Architectural Science Association and The University of Adelaide. https://doi.org/10.17605/OSF.IO/BPWA3.

Persistent Link:

http://hdl.handle.net/11343/123149 